\title{
Pricing Strategies of Software Vendors
}

\author{
Pricing strategies of vendors in the software industry have so far not been discussed compre- \\ hensively. This is surprising as the characteristics of the software industry differ particularly \\ from other industries. This paper provides an overview of pricing models for software. We \\ will take into account the characteristics of software as a product as well as the software \\ industry's general conditions. Furthermore, we refer to recent software delivery models, such \\ as software as a service. The results are based on literature research and empirical studies.
}

\section{DOI 10.1007/s12599-009-0075-y}

\section{The Authors}

Dipl.-Wirtsch.-Ing. Sonja Lehmann
Prof. Dr. Peter Buxmann
TU Darmstadt
Chair of Information Systems
Hochschulstr. 1
64289 Darmstadt
Germany
\{lehmann | buxmann\}@
is.tu-darmstadt.de

Received: 2008-11-07

Accepted: 2009-03-02

Accepted after one revision

by Prof. Dr. Buhl.

This article is also available in German in print and via http://www.wirtschafts informatik.de: Lehmann S, Buxmann P (2009) Preisstrategien von Softwareanbietern. WIRTSCHAFTSINFORMATIK. doi: 10.1007/11576-009-0197-3.

\section{Introduction}

Pricing takes a central role in the strategy of most companies (Simon 1992, p. 7; Diller 2008, p. 21-22; Rullkötter 2008, p. 93). It directly determines the turnover level and thus in the long term also the achieved returns. In case of erroneous decisions, the company's reputation and customer relations can be at risk. Despite this high importance, a multitude of deficiencies regarding pricing models can often be identified, including rationality deficits in form of ad hoc or arbitrary decisions (Florissen 2008, p. 85).

In this paper, we examine pricing strategies of software vendors. Traditional pricing concepts, however, cannot eas- ily be applied to software products (Bontis and Chung 2000, p. 246). The reason is that the software industry is subject to economic rules fundamentally different to other industries (Buxmann et al. 2008a, p. 1). For example, the software industry is often characterized by network effects (Shy 2001, p. 1) influencing the value of a product for customers through its prevalence rate (Katz and Shapiro 1985, p. 424). This might cause lock-in effects on the customer side that also create new opportunities with regard to pricing models.

Furthermore, we have to take into account that software is offered or obtained in various ways. With regard to the provisioning of software, we can today observe an increasing trend towards on-demand solutions besides traditional on-premise software. In so-called software as a service (SaaS) solutions the user purchases standard software via the Internet without the need to install the software locally (Buxmann et al. 2008b, p. 500). In addition to proprietary solutions also free and open source software (FOSS) exists. As software in business models of open-source software providers is usually free, in most cases sales are realized by supplementary services, such as consulting, implementation, documentation, and maintenance (Hecker 1999). As in that case the design of pricing models does not relate to software, we do not intend to dwell on this type of software in more detail.

Against this background, the aim of this paper is to identify various fundamental pricing models for software and to examine their specific implications for the software industry. Moreover, we will introduce the views of providers and users and their assessment of different pricing models. The results are based on literature research and empirical studies, includ- ing interviews with experts conducted in November and December 2007 in order to analyze the user perspective. We interviewed ten CIOs from companies deploying standard application software for ERP. As this is an exploratory study, we chose companies from different industries and of different sizes. In terms of size we interviewed companies with 800 to 260.000 employees. The interviews were based on a structured guideline.

In the following sections we will first analyze the general conditions and characteristics of the software industry which are relevant to pricing. In section 3 we provide an overview of the possible parameters of pricing models for software products and their various characteristics. In section 4 we present empirical results on the topic of software pricing models. The paper concludes with a summary and an outlook.

\section{General conditions and characteristics of the software industry}

The design of a pricing model requires the consideration of the characteristics of the product to be sold and the market conditions in the respective industry. As software is a digital good, the economic theory of digital products provides a first starting point for the development of pricing strategies for software providers.

Fundamental characteristics of digital goods are indestructibility, transmutability, and reproducibility (Choi et al. 1997, pp. $69 \mathrm{ff})$.

Indestructibility becomes apparent by the unascertainable difference between new and used digital goods - there is no loss of quality as a result of using the good. 


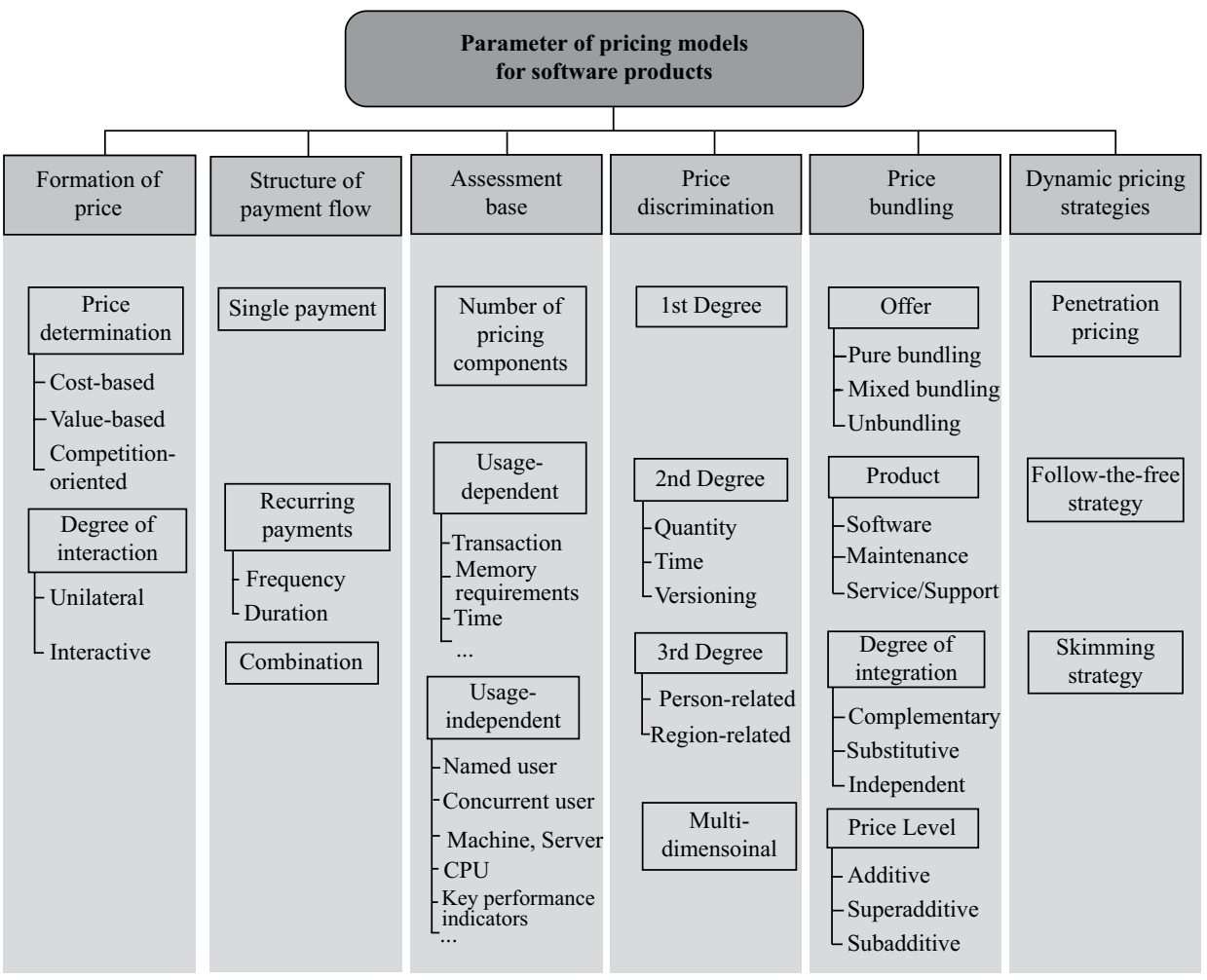

Fig. 1 Parameters of pricing models for software products

software constitutes an experience good whose actual value can be assessed by the customer only after its purchase (Buxmann et al. 2008a, p. 137).

The possibilities of pricing for software products are also determined by the Internet and its characteristics. Thus, the Internet can be used for the distribution of digital products (Albers et al. 2000, p. 80). This can significantly reduce distribution costs and increase the potential clientele. In general, reduced transaction costs (Bakos 1998, p. 35) lead to a multitude of new possibilities, such as a more flexible pricing model, new pricing mechanisms, and billing systems for micropayments. Furthermore, the easier interaction between customer and supplier is one of the Internet's characteristics, e. g. in that it enables the implementation of regular price changes with little effort (Skiera et al. 2005, p. 286). It is even economically possible to address every customer individually due to the Internet's characteristics (Skiera et al. 2005, p. 286).

Another feature of software markets arises from the existence of network effects. This means that the value a software solution provides for a customer not only depends on the properties of the solution, but also on the number of users. The larger the network is, the better it usually is for the user. We distinguish between direct and indirect network effects (Katz and Shapiro 1985): Direct network effects arise because the users can communicate with each other more easily and thus more cost-effectively by means of sharing software standards or common technologies. In contrast, indirect network effects result from the dependence between the consumption of a basic good and the consumption of complementary goods and services. Therefore, a high spread of standard software leads to an increasing offer of consulting services, which in turn results in a growing attractiveness of the software solution for the customers.

These network effects have a significant impact on software markets and hence are reflected in the strategies of the software vendors. Thus, in many cases we can observe lock-in effects on software markets that lead to a solution which often is not technically optimal (Arthur 1996), and therefore complicates the market entry for competitors and binds customers to the current provider due to switching costs (Shapiro and Varian 1999, p. 103-104). Since frequently one supplier succeeds in a specific software industry segment, this is also referred to as "winner takes it all markets" (Arthur 1996; Bakos 1998, p. 4). In those areas of the software industry with less strong network effects the formation of oligopolies results from the coexistence of standards and companies (Skiera et al. 2005, p. 288). However, there is an ongoing 
discussion whether SaaS solutions lead to a reduced provider dependence. Reasons are especially seen in smaller customizing options as well as in the frequent use of open standards.

This possibly may result in a lower lockin effect for SaaS products. High switching costs also arise from necessary changes in the organizational structure if software and business processes are strongly linked. Therefore, lock-in effects and switching costs usually cannot be avoided even for SaaS solutions in the field of enterprise software (Buxmann et al. 2008b, p. 501).

The above mentioned characteristics and conditions are of high importance for the pricing of software products. Therefore, they have to be considered in particular as regards the design of pricing strategies.

\section{Parameters of pricing models for software products}

The design options for software products are diverse. In the course of time, fundamental changes in software pricing models have occurred. While in times of mainframe computers pricing was usually based on computing power, user-oriented pricing models ("licensing models") have become widely accepted in the recent past (Bontis and Chung 2000, p. 247-248). Today, software vendors increasingly offer usage-based pricing models (Sundararajan 2004, p. 1660; Buxmann et al. 2008a, p. 12-13).

Since there is no universal pricing model for software providers (Bontis and Chung 2000 , p. 246) and pricing models may consist of several elements, this paper provides different pricing parameters for software products. Fig. 1 shows the parameters of the pricing models we are examining in the following subsections.

The software vendors' pricing models usually consist of a combination of different parameters. The pricing model may also include several sub-points from each column.

\subsection{Formation of prices}

During the formation of prices the providers settle how the level of prices should be laid down. This requires considering the basis of price determination on the one hand, and the degree of interaction on the other.
For determining the price, basically three forms are possible (Homburg and Krohmer 2006, p. 720; Nieschlag et al. 2002 , p. $810-814$ ):

- cost-based

- demand-driven or value-based, and

- competition-oriented.

Following the approach of cost-based pricing, the price level is established using cost accounting (Diller 2008, p. 310-311). For digital goods, however, this form of price determination is of little importance because of their special cost structure. Shapiro and Varian (1999, p. 3) summarize this as follows: "cost-based pricing just doesn't work [...]. You must price your information goods according to consumer value, not according to your production cost." Therefore, cost-based pricing is not suitable for software licenses. In contrast, price determination based on costs can make good sense for SaaS.

Demand-driven or value-based pricing respectively is essentially based on the demand for the product (Homburg and Krohmer 2006, p. 720-721). Here, the appreciation of the customers for the product is of importance instead of the product's cost (Harmon et al. 2005, p. 1).

For competitive price determination, the formation of prices is aligned to the prices and the price-related behavior of competitors (Homburg and Krohmer 2006, p. 747). The attractiveness of competing products for customers depends on the homogeneity of the products and the market structure among others (Nieschlag et al. 2002, p. 813). In the software industry, obtaining a large market share is of crucial importance for the providers due to network effects and the resulting lock-in effects on the customer side, especially if the product does not or only slightly differ from the products of competitors. Therefore, competitive pricing plays an important role for software products in addition to demand-based pricing.

Another pricing parameter is the degree of interaction. Non-interactive pricing is characterized by the unilateral determination of the price by the provider without the customer's influence. In the case of interactive pricing, the price results from customer and supplier agreement. Examples of interactive price formation are negotiations or (Internet) auctions (cf. e. g. Schmidt et al. 1998). However, in most cases auctions for digital goods and therefore also for software products make lit- tle sense economically (Shapiro and Varian 1999, p. 23).

\subsection{Structure of payment flow}

When designing software pricing models there are basically two options: Either the customer makes a single payment and thus obtains perpetual rights of use for the software or the pricing model requires regularly recurring customer payments. Also the combination of the two variants is possible (Kittlaus et al. 2004, p. 82).

Single payments correspond to the widely used model of software licensing today. By purchasing a license, the customer acquires a temporarily unlimited right of use.

The possibilities in design of regularly recurring payments can be seen in both frequency and in the duration of payments. For example, customers and providers can agree upon a monthly or annual subscription price over a period of two years as a pricing model for using the software. These pricing models are particularly frequent in SaaS solutions (Cusumano 2007, p. 20) where customers use the provider's software during the period of payment (also referred to as subscription or rental models) via the Internet (Buxmann et al. 2008b). From the user's perspective, this pricing model has the advantage that the software can be used economically for short periods as the monthly payments are usually less than a single payment for a software license (Cusumano 2007, p. 20). This advantage from the customer's perspective, however, entails greater financial demands for the provider. Thus, SaaS providers often have difficulties yielding profitability for the company (Hill 2008, p. 48). According to a survey of SIIA et al. (2006, p. 5), U.S. software providers expect a greater distribution of subscription models in future instead of single payments in form of purchasing a license.

Moreover, also hybrid forms of single and regular payments are possible. For example, it is common to purchase a software license which is linked to a software maintenance contract. This usually stipulates annual payments in the amount of a fixed percentage of the (single) license payment. In current pricing models of many software providers the maintenance percentage is about $20 \%$. This model has the advantage for the providers that payments will flow relatively steadily. 


\subsection{Assessment base}

Another design possibility is related to determining the assessment base of the pricing model. This can be done e. g. per user or in dependence on the utilized time. It is also strongly linked to the customer's impression whether the pricing model of the provider is considered to be fair.

First, the number of price components (Skiera 1999b) making up the pricing model is fixed. Any price component is based on assessment. For example, the pricing model can be divided into a usage-independent basic amount to be paid monthly and in a usage-dependent component, such as used storage capacity. Skiera (1999b) was able to show that service companies can yield significant profit improvements through the use of two price components compared to a pricing model with only one price component.

As already indicated in the example, the assessment base can be either usagedependent or usage-independent. Basically, a variety of parameters is possible here. They may also be industry-specific, e. $g$. the number of managed rental properties can serve as assessment base for software supporting the management of apartments.

Tab. 1 shows examples of a usage-dependent assessment base.

The use of a usage-dependent assessment base can lead to fixed and variable administrative costs, for example for usage monitoring and billing. Even in the case of low error rates in the creation of bills it should be considered that accounting errors may lead to customer annoyance. This could possibly result in a decline of orders in the future (Sundararajan 2004, p. 1661).

A usage-independent assessment base is constituted of variables that are not related to the actual use of software. Tab. 2 shows examples of a usage-independent assessment base.

In support of usage-independent assessment bases providers may argue that customers usually are willing to pay more for the option of unlimited use (Sundararajan 2004, p. 1661). However, many customers overestimate their usage behavior (Flatrate-Bias) (Lambrecht and Skiera 2006 , p. 221). In section four we will analyze the question of usage-(in-)dependent pricing models again from the user's perspective.

\begin{tabular}{|c|c|}
\hline Assessment base & Description \\
\hline Transaction & $\begin{array}{l}\text { The price depends on the number of transactions executed } \\
\text { by the software. This can be a technical assessment base (e. g. } \\
\text { Web Service invocation) or an assessment base with regard } \\
\text { to contents (e. g. number of crawled delivery items). }\end{array}$ \\
\hline Memory requirements & The price is ascertained by units of memory requirements (e. g. per GB). \\
\hline Time & $\begin{array}{l}\text { The amount of the price is determined by the actual } \\
\text { duration of software usage (e. g. price per minute). }\end{array}$ \\
\hline
\end{tabular}

Tab. 2 Examples of a usage independent assessment base

\begin{tabular}{|ll}
\hline Assessment base & Description \\
\hline Named user & $\begin{array}{l}\text { The right to use the software is bounded to a specific } \\
\text { person and therefore the price refers to a defined user. }\end{array}$ \\
\hline Concurrent user & $\begin{array}{l}\text { This pricing unit allows the simultaneous use of the } \\
\text { software with a pre-defined number of users. } \\
\text { Customers will be charged for each server or machine. The } \\
\text { rights of use are bounded to this server or machine. }\end{array}$ \\
\hline Server/machine & $\begin{array}{l}\text { The price of the software refers to the amount of CPUs in use. } \\
\text { CPU }\end{array}$ \\
\hline Master data & $\begin{array}{l}\text { The price of the software refers to the number of entered } \\
\text { master data (e. g. customers, suppliers, employees, } \\
\text { inventory, rental units, land parcels, managed assets). }\end{array}$ \\
\hline Locations & $\begin{array}{l}\text { The price applies per location. This includes } \\
\text { special forms of locations (e. g. mines). }\end{array}$ \\
\hline Produced amount & $\begin{array}{l}\text { The software is priced according to the production of } \\
\text { the customer (e. g. produced barrels oil per day). }\end{array}$ \\
\hline Key performance indicators & $\begin{array}{l}\text { The price refers to Key Performance Indicators } \\
\text { (e. g. revenue, expenses, budget). }\end{array}$ \\
\hline
\end{tabular}

While SaaS solutions generally enable many possibilities regarding the assessment base, usage-independent variables, such as the number of users, are widely used. However, there are also some examples of transaction-based pricing models (Schwartz 2007, p. 6).

Apart from its fundamental importance of the assessment base for the customers, the assessment base is necessary for price discrimination. This will be examined in the following.

\subsection{Price discrimination}

Another parameter of software pricing is price discrimination. Price discrimination basically means offering the same products to different buyers at different prices (e. g. Diller 2008, p. 227; Skiera and Spann 1998; Pepels 1998, p. 89). The provider's objective is an improved absorption of consumer surplus. Compared to a pricing model with a standard price, this can be achieved by taking into account a customer's specific willingness to pay. When users identify different product benefits, the provider can realize higher total turnovers by differentiated prices (Diller 2008, p. 227).
Price discrimination is particularly important for providers of digital goods as it allows selling them to customers with a lower willingness to pay due to low variable cost of digital goods. In addition, the simple and inexpensive modification of digital goods promotes the application of price differentiation strategies.

Pigou (1929) distinguishes three forms of price discrimination: price discrimination of first, second, and third degree.

In first-degree price discrimination each customer receives a price offer in the amount of his/ her willingness to pay. In practice, e. g. in the software industry, the implementation of this type of price discrimination is difficult. The main reason is the providers' lack of detailed knowledge of the customers' willingness to pay - in particular of each single customer (Choudhary et al. 2005, p. 1120).

The second-degree price discrimination plays an important role for digital goods (Linde 2008, p. 209). It is based on the principle of self-selection, i. e. the customer decides which product-price combination he chooses (Varian 1997, p. 193). Skiera (1999a, p. 287) distinguishes between 
quantity-, time-, and performance-related price discrimination for this case $\mathrm{e}^{1}$.

For quantity-based price discrimination, the average price per unit changes in accordance with the total quantity purchased. This also includes the flat rate as the average price per unit depends on the overall usage of the customer (Skiera and Spann 2000). This kind of quantity discounts is widely used for software licenses, especially for key accounts.

The time-based price discrimination is aimed at customers who are willing to pay more or less at different points in time (Skiera and Spann 1998). Prices may, for example, differ depending on the time of day or season. Prices for information can also be differentiated according to the delay with which they are made available for the customer (Skiera and Spann 2000).

Another form of price discrimination with self-selection is made up by performance-based price discrimination. This type occurs when relatively minor changes are made in scope or quality of the offers (Diller 2008, p. 237). These product variants are offered at different prices. In the context of product differentiation this is also often referred to as versioning (Varian 1997; Viswanathan and Anandalingam 2005).

Offering different versions of a product is regarded as profitable particularly for digital goods as a result of their cost structure (Viswanathan and Anandalingam 2005, p. 269). Against the background of network effects, inexpensive alternatives can lead to a greater market penetration. This shows that software products generally exhibit good prerequisites for this form of price discrimination (Bhargava and Choudhary 2008, p. 1029). Software vendors often first develop a high quality and extensive product before removing certain features in order to be able to offer different versions to the customers (Shapiro and Varian 1999, p. 63; Buxmann et al. 2008a, p. 115-116). An example of performance-related price discrimination are the versions "Home Basic", "Home Premium," "Business", and "Ultimate" of Microsoft Windows Vista which differ in terms of functionality and price.

With regard to the number of versions, we have to take into account that a multitude of versions can be confusing for

\footnotetext{
Due to its minor importance in the software industry search-related price
} discrimination was omitted. customers and at the same time incurr increased efforts on the part of the supplier (Viswanathan and Anandalingam 2005, p. 269). As a result of extremeness aversion, i. e. the averseness to extremes, it is recommended to offer three versions of information goods so that the customer can decide for the version in the middle as a compromise solution (Varian 1997, p. 200; Simonson and Tversky 1992; Smith and Nagle 1995). Bhargava and Choudhary (2008) suggest that companies should consider further versions of lower quality in case of declining variable costs. The authors formally show that with decreasing variable costs versioning becomes advantageous for providers. This is regarded as a result of the gain of additional customers with a lower willingness to pay (Bhargava and Choudhary 2008, p. 1031).

The third-degree price discrimination is based on the supplier's market segmentation (e. g. Diller 2008, p. 229). In contrast to second-degree price discrimination, customers cannot make a choice on their own. The third-degree price discrimination can be divided into personal and regional discrimination (Skiera and Spann 2000).

In the software industry personal price discrimination is used e.g. in the case of lower prices for students or, more generally, for private use compared to licenses for commercial purposes. For this form of pricing a proof of identity is important, such as by certificates in the software industry (Skiera and Spann 2000). Different prices depending on the country as a form of regional price discrimination are particularly used for pricing of consultancy services.

In case of price discrimination in more than one dimension we speak of multidimensional price discrimination (Skiera and Spann 2002, p. 279). In practice, this is widely used. For example, a simultaneous regional and quantitative price discrimination is possible. In this case, the provider has different prices for each country or region in addition to a pricing model depending on the sales volume. The aim of multidimensional price discrimination is a finer segmentation of customers. This allows an improved absorption of existing differences in willingness to pay. It should be noted, however, that the complexity of the pricing model should still be ascertainable for the buyer and billing should remain feasible for the provider (Skiera and Spann 2002, p. 279).

\subsection{Price bundling}

Price bundling is another pricing parameter for software products. In general, price bundling is understood as the compilation of several identifiable sub-services (products, services and/ or rights) of one or more providers to a package of offers ("Set") with a specification of a total price (Diller 2008, p. 240). Price bundling can also be considered as a special case of price discrimination (e. g. Skiera et al. 2005, p. 290; Diller 2008, p. 240). As a result of its high relevance for the software industry, we will examine this issue of price bundling for pricing of software products separately.

The objectives related to price bundling vary. First and foremost, price bundling is used for price discrimination (see section 3.4) (Viswanathan and Anandalingam 2005 , p. 264). While conventional methods of price discrimination require rather detailed knowledge of the reservation prices of individual products, this is necessary to a lesser extent for price bundling (Adams and Yellen 1976, p. 476). Bakos and Brynjolfsson (1999) explain this with the law of large numbers. Accordingly, it is easier for the vendor to forecast the willingness to pay for a bundle with a variety of products than for each product individually, as the willingness to pay distribution has a smaller number of extreme values for the bundle (Viswanathan and Anandalingam 2005, p. 264). Wu et al. (2008, p. 608609) argue, however, that this is only applicable when no variable costs occur; even if the variable costs are very low, significant costs for a bundle with many elements arise and put the potential benefits of bundling into perspective.

Especially in the software industry, which is characterized by network effects, bundling can be beneficial for suppliers as it supports a greater distribution of (additional) products on the market. For example, the Adobe Creative Suite software contains software for creating PDF files in addition to photo editing and layout design. Therefore, the sales of the Creative Suite also foster the proliferation of PDF documents. Furthermore, the bundling strategy may impede the entry of potential competitors (Nalebuff 2004), for instance of suppliers who just offer one of the products from the bundle. Moreover, bundling may also serve the aim of saving costs in invoicing and delivery as multiple products are sold simultaneously in 


\section{We proudly present}

BUSINESS \& INFORMATION SYSTEMS ENGINEERING 


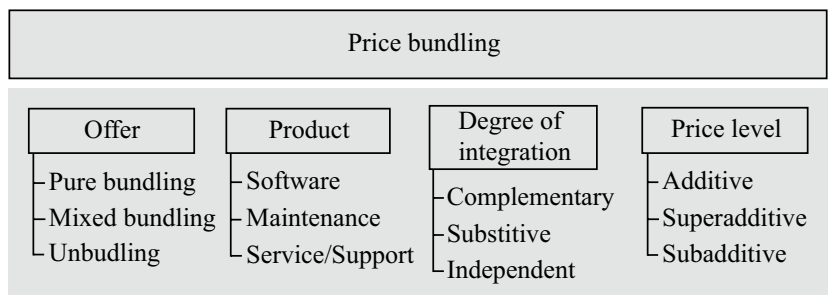

Fig. 2 Aspects of price bundling

one process (Viswanathan and Anandalingam 2005, p. 264; Adams and Yellen 1976, p. 475-476).

In the following, we want to dwell on the aspects of price bundling as shown in Fig. 2 before subsequently discussing the factors influencing the advantages of bundling strategies.

Depending on the type of the software vendor's offer, the three forms of pure bundling, mixed bundling, and unbundling can be distinguished. In the case of pure bundling, the products are offered exclusively in a bundle. If the customer can choose whether to buy the entire bundle or the single products separately, this is called mixed bundling. Unbundling occurs when the customer can only purchase the products separately (Adams and Yellen 1976; Schmalensee 1984, p. 212; Olderog and Skiera 2000, p. 140). Another variant is customized bundling which allows the customer to choose within certain specifications which of the products should be contained in the bundle. The vendor just determines the bundle's price and scope (Hitt and Chen 2005). Wu and Anandalingam (2002) show that offering several customized bundles can be beneficial for a monopolistic provider of information goods. Assuming incomplete information, Wu et al. (2008) identified that customized bundling is more promising for the provider than pure bundling or unbundling.

Another aspect of price bundling is the type of product. The partial offers of the bundle can be quite different in nature. In the software industry the product type will primarily be the software itself, its maintenance and service and support services. Today, the turnover of a software vendor is typically separated into three equal parts of licenses, maintenance, and services (Cusumano 2007, p. 19). The offers from these three areas can be offered as a bundle in different forms.

Furthermore, the products in the bundle can also be described as regards their degree of integration. In this respect, partial offers of the bundle can be comple- mentary (Diller 2008, p. 241) or, respectively, can substitute or be independent of each other. Bakos and Brynjolfsson (1999) found that bundling a large number of unrelated information goods can be profitable. Their model also allows the analysis of complementary and substitutive bundle elements.

The bundle's price may be determined in an additive, superadditive, or subadditive method. In case of an additive bundle, the bundle price corresponds to the sum of the individual prices. In case of a superadditive package, the price of the bundle is above the sum of the parts of the bundle, while a subadditive set has a price below that amount (Diller 2008, p. 240-241). The last variant, i.e. a bundle with discounts to individual prices, is referred to as normal case (Diller 2008, p. 241; Viswanathan and Anandalingam 2005, p. 264). Günther et al. (2007, p. 139) found out in their study that the majority of respondents expect a lower total price for the bundle when purchasing composite web services. For example, the price for the bundle of Microsoft Office is well below the sum of the individual prices of its components. At the time when Microsoft delivered its operating system Windows as a bundle with the media player, the customers had the impression that this product was added for free. This form of bundling strategy can, for example, also be used to add new applications to older products in order to induce the customer to draw upon upgrade or maintenance services (Cusumano 2007, p. 20). However, it should be kept in mind that a bundling of products may be opposed to competition laws. An example of this is the European Commission's proceedings against Microsoft because of the bundling of its operating system Windows with the Internet Explorer (Buxmann et al. 2008a, p. 30).

On the basis of Schmalensee's (Schmalensee 1984) studies, factors influencing the benefits of bundling have been examined by Olderog and Skiera (2000) among others. In the presence of a negative correlation of reservation prices for different products bundling may lead to a more homogeneous demand structure. Furthermore, bundling strategies tend to be more advantageous the lower the variable costs. Therefore, price bundling for software products is of particular interest. It is also worth noting that the optimal number of products in a bundle may also be determined by existing budget constraints on the client's side for example (Bakos and Brynjolfsson 1999).

\subsection{Dynamic pricing strategies}

Dynamic pricing strategies are based on a multi-periodic space of time. For the software industry, the penetration strategy, the follow-the-free strategy, and the skimming strategy are of particular significance (Buxmann et al. 2008a, p. 122).

The penetration strategy has the objective to use low prices in order to maximize market penetration (Dean 1950, p. 50). This is especially important for software vendors during market entry if alternative software systems already have a large installed base (Buxmann 2002). At a later stage - after reaching a critical mass - it may be possible for the vendor to increase prices. Conditions for a sensible use of this strategy are the existence of network effects and economies of scale as well as switching costs (Skiera et al. 2005, p. 288). Ahtiala (2006) showed in experiments that against the backdrop of software piracy it is beneficial for software vendors to initially sell very cheap software to create a lock-in effect and later offer upgrades at a higher price. As a result of the low variable costs of digital goods and the existence of network effects and switching costs, this strategy is widely used in the software industry. An example of a penetration strategy can be seen in high price discounts for first time customers.

In the case of the follow-the-free strategy, customers receive a product free of charge. The vendor's objective is to create a lock-in effect on the users' side in order to generate revenues later on by means of complementary products or premium versions (Zerdick et al. 1999, p. 191-194). For example, we can think of offering a software product free of charge while the associated services, such as installation, maintenance, training, and customizing must be paid for (Cusumano 2007, p. 21). A prominent example from the software industry is the strategy of the 
Fig. 3 Assessment bases preferred by software vendors and users (SIIA et al. 2006, p. 7)

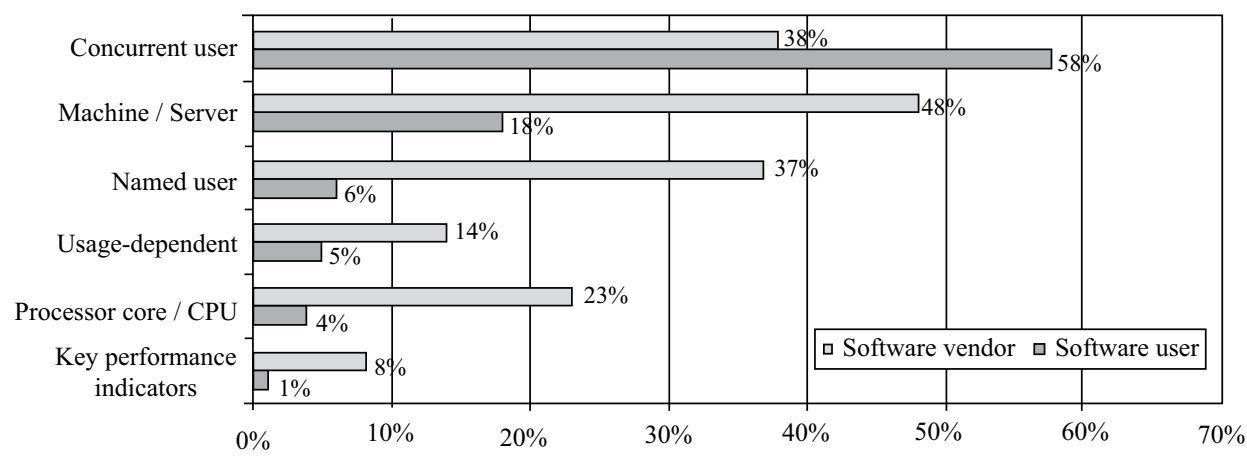

software vendor Adobe who was able to set the PDF standard with its free Acrobat Reader. While the software for reading PDF documents has been given away to users for free, Adobe was able to generate revenues by selling the software for creating PDF documents (Buxmann et al. 2008a, p. 123-15; Cusumano 2007, p. 21).

Furthermore, basically also the skimming strategy might be used (after Dean 1950 , p. 49). Here, a rather high starting price may be gradually reduced in the course of time. The aim is to reach customers with a high willingness to pay first and to skim consumers with lower reservation prices later by a lower price (Buxmann et al. 2008a, p. 125). In the software industry, this pricing strategy is infrequently used, however.

\section{Pricing strategies of software vendors - Empirical results}

In this section we will investigate how different pricing and licensing models are assessed by vendors and users. Since few empirical results are available in this area, existing studies are usually based on just a few parameters of software pricing.

Below we consider a study by the Software \& Information Industry Association from 2006, which only examines the parameters of the assessment base in relation to pricing. We supplement this study with results of expert interviews with users conducted in 2007. Basically, it is possible that an observation at different times might have a distorting effect. From our point of view, there are no influencing factors for the period from 2006 to late 2007 that suggest a change of conditions and therefore a distortion. The objective of our consideration is to analyze the views of users and their backgrounds in greater detail. However, we have to keep in mind that the interviews constitute a qualita- tive, non-representative sample among ERP users.

The Software \& Information Industry Association has conducted a survey among 698 experts. They interviewed 487 software vendors and 211 users (SIIA et al. 2006). Fig. 3 shows an overview of the various licensing models and the extent to which software vendors or users prefer these models.

Pricing on the basis of concurrent users is among the favorites of the users as regards the possible usage-independent assessment bases for software products (see also section 3.3). Moreover, also licensing based on servers or machine is interesting for the user - with considerably less popularity however. Only a few customers favor an assessment according to the named user or processor. Just $1 \%$ of the users support the assessment based on financial ratios, which thus constitutes the least desired form (SIIA et al. 2006, p. 7).

In the following, we will also examine pricing models with a usage-dependent assessment base in more detail as a key result of the survey is that software vendors expect a greater dissemination of this model (see Fig. 4).

The results also show, however, that many users increasingly reject usagedependent licensing models, as Fig. 5 suggests.

All in all, only a quarter of the customers were satisfied with the pricing and licensing strategy of the providers according to the SIIA study.

In the following, we will have a look at the results of the expert interviews to obtain an idea of what reasons might make the user assess certain pricing models positively or negatively.

Usage-dependent pricing models for software were only considered as an interesting alternative by three of ten respondents. Seven respondents expressed skepticism to opposition for this pricing model.
Reasons for this were seen in the difficult forecast of the resulting costs as well as in the potentially significant cost fluctuations due to different usage intensities. In addition to the cost estimate, also the determination of the assessment base was classified as difficult. It was regarded as essential for such a model that the measuring effort should not be too large and that the model is easy and understandable for the user. With regard to its structure the model, however, partly corresponds to the conception of fairness of some respondents - these are willing to pay more for a high usage of the software in terms of a value-based pricing model.

The participants considered it to be problematic that most of these models are structured in a way that the user pre-purchases a usage quota. Quite often a supplementary payment becomes necessary if the actual use of the previously proposed quota is exceeded. If the quota is not fully utilized, the user usually does not receive any refunds or credits.

The users tend to negatively asses the currently used pricing models of software vendors. One reason was seen in the complexity of pricing models, including their combinations with each other. In this context, the users also addressed their dissatisfaction with IT outsourcing service providers. In their opinion these tended to optimize their services according to technical criteria, which often lead to a "zoo of licenses" on the customer side.

One of the respondents expressed satisfaction regarding the conditions for large enterprises. High discounts, however, were given only for licenses and not on maintenance fees. The reason for this can be seen in the accounting rules. Software vendors balancing in accordance with U.S. GAAP must specify a so-called "fair value" for the realization of anticipated revenues for multi-element arrangements (bundling) for outstanding maintenance services, 

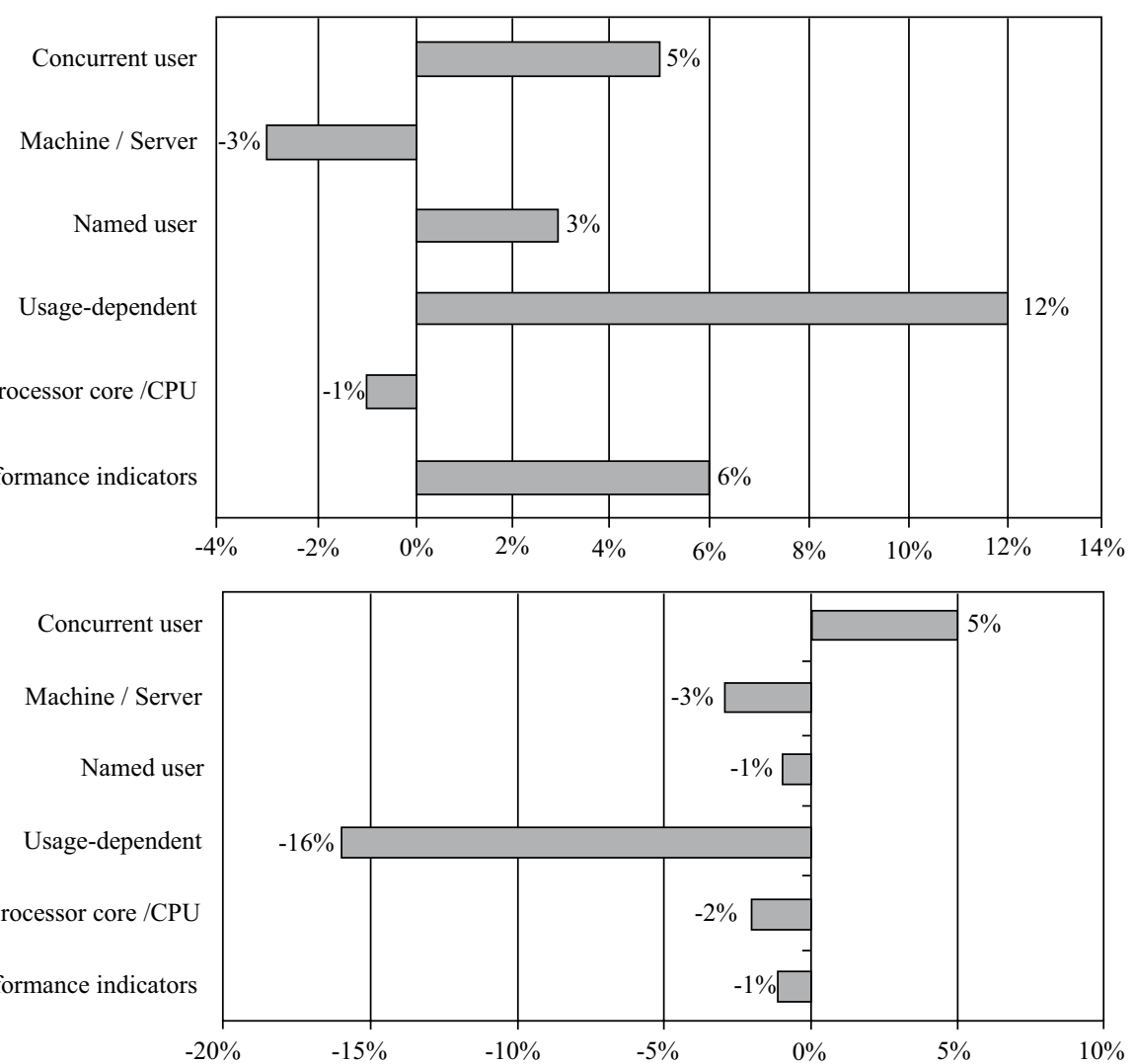

Fig. 4 Expected changes in the assessment bases until 2008 from the vendors' perspective (SIIA et al. 2006, p. 7)
Fig. 5 Change in user preferences with regard to the use of different assessment bases from 2005 to 2006 (SIIA et al. 2006, p. 7) which can be reliably ascertained. For this reason, these software vendors do not provide discounts on maintenance services (Suermann 2006, p. 112-114).

Almost half of the respondents claimed more flexible pricing models in response to the question of which aspects of pricing models should be modified from the user's point of view. Here, the desired flexibility refers to the periodic adjustment to the changing number of users, a temporary usage (including "usage breaks"), and new assessment variables regardless of the number of users. However, it should be noted that flexible pricing models may also be to the detriment of the customers as the provider can use this flexibility for his own benefit. This is particularly possible for ERP software since significant switching costs can arise for changing the provider. Consequently, it remains unclear in the end who will benefit from flexible pricing models.

Regarding the pricing of SaaS solutions, a usage-dependent assessment base (four consents) and a flat fee (five consents) were proposed by the users. As an opportunity, the respondents mentioned the temporary usage as well as the reduction of entry barriers or, respectively, the good predictability of costs in the flat fee model. In addition, a short period of cancelation was required, although one IT manager also noted the corresponding risks. When using shorter usage intervals, the customers are not bound as long as in case of classical outsourcing, for example.

\section{Summary and outlook}

In this paper, we presented and analyzed different parameters of possible pricing models for software products, taking the economic specifics of the software industry into account. We examined the six parameters formation of prices, structure of payment flow, assessment base, price discrimination, price bundling, and dynamic pricing strategies. In general, pricing models of software vendors can be attributed to a combination of these parameters. For the software industry, particularly the design of the assessment base is very specific. Here, units can either be determined depending on the usage of the software or usage-independently. Moreover, low price and price bundling strategies are often profitable because of the low variable costs for software licenses.

Based on a SIIA study among users and providers we have analyzed assessments of current and future pricing models. From the user's point of view, usage-independent assessment bases, such as concurrent users, are supported. On the other hand, usage-dependent variables, such as payment for transactions, are increasingly being rejected. Software vendors, however, expect a greater importance of the usagedependent pricing models in future. In order to assess the background of these evaluations expert interviews were conducted among users. The main reasons stated against usage-based pricing models were the problematic cost calculation and the selection of a concrete, meaningful assessment base.

New forms of software provision, such as SaaS, represent a new challenge for the design of pricing models. Even if current software offers for companies are primarily billed on a usage-independent basis, also the application of usage-dependent pricing models seems possible in this area. In this case, the assumption of negligible variable costs cannot be maintained for SaaS providers as the fees usually include service and maintenance offers for the users on the one hand and on the other hand also have to provide server capacity. These costs are partly of a variable nature.

When considering the pricing of SaaS providers we also have to take into account 
that many software companies are planning to in future offer SaaS solutions in addition to their product range (Lünendonk 2007, p. 135). This is linked to the so-called multi-channel problem, i. e. the problem that the provider strategies also have to consider possible cannibalization effects. For the vendor, this means that this aspect not only has to be considered in product design but also concerning pricing strategies.

\section{References}

Adams WJ, Yellen JL (1976) Commodity bundling and the burden of monopoly. The Quarterly Journal of Economics 90(3):475-498

Ahtiala P (2006) The optimal pricing of computer software and other products with high switching costs. International Review of Economics and Finance 15(2):202-211

Albers S, Clement M, Skiera B (2000) Wie sollen die Produkte vertrieben werden? Distributionspolitik. In: Albers S, Clement M, Peters K, Skiera $B$ (eds) eCommerce. Einstieg, Strategie und Umsetzung im Unternehmen. 2nd edn. F.A.Z. Institut, Frankfurt am Main, pp 79-94

Arthur WB (1996) Increasing returns and the new world of business. Harvard Business Review 74(4):100-109

Bakos Y (1998) The emerging role of electronic marketplaces on the internet. Communications of the ACM 41(8):35-42

Bakos Y, Brynjolfsson E (1999) Bundling information goods: pricing, profits and efficiency. Management Science 45(12):1613-1630

Bhargava K, Choudhary V (2008) When is versioning optimal for information goods? Management Science 54(5):1029-1035

Bontis N, Chung H (2000) The evolution of software pricing: from box licenses to application service provider models. Electronic Networking Applications and Policy 10(3):246-255

Buxmann P (2002) Strategien von Standardsoftware-Anbietern: Eine Analyse auf der Basis von Netzeffekten. Zfbf 54:442-457

Buxmann P, Diefenbach H, Hess T (2008a) Die Softwareindustrie: Ökonomische Prinzipien, Strategien, Perspektiven. Springer, Heidelberg

Buxmann P, Hess T, Lehmann S (2008b) Software as a Service. WIRTSCHAFTSINFORMATIK 50(6):500-503

Choi SY, Stahl DO, Whinston AB (1997) The economics of electronic commerce: the essential of doing business in the electronic marketplace. Macmillan, Indianapolis

Choudhary V, Ghose A, Mukhopadhyay T, Rajan U (2005) Personalized pricing and quality differentiation. Management Science 51(7):11201130

Cusumano MA (2007) The changing labyrinth of software pricing. Communications of the ACM 50(7):19-22

Dean J (1950) Pricing policies for new products. Harvard Business Review 28:45-53
Diller H (2008) Preispolitik, 4th edn. Kohlhammer, Stuttgart

Fishburn PC, Odlyzko AM (1999) Competitive pricing of information goods: subscription pricing versus pay-per-use. Economic Theory 13:447470

Florissen A (2008) Preiscontrolling - Rationalitätssicherung im Preismanagement. Zeitschrift für Controlling und Management 52(2):85-90

Günther O, Tamm G, Leymann F (2007) Pricing web services. International Journal of Business Process Integration and Management 2(2):132140

Harmon R, Raffo D, Faulk S (2005) Value-based pricing for new software products: strategy insights for developers. http://www.cpd.ogi.edu/ MST/CapstoneSPR2005/VBSP.pdf. Accessed 2009-03-10

Hecker F (1999) Setting up shop: the business of open-source software. IEEE Software 16:45-51

Hill S (2008) SaaS economics seem to favor users more than vendors. Manufacturing Business Technology Jan. 2008, p 48

Hitt LM, Chen P (2005) Bundling with customer self-selection: a simple approach to bundling low marginal cost goods. Management Science 51(10):1481-1493

Homburg C, Krohmer H (2006) Marketingmanagement. Strategie - Instrumente - Umsetzung - Unternehmensführung, 2nd edn. Gabler, Wiesbaden

Katz ML, Shapiro C (1985) Network externalities, competition, and compatibility. American Economic Review. Number 75:424-440

Kittlaus H, Rau C, Schulz J (2004) Software-Produkt-Management. Springer, Heidelberg

Lambrecht A, Skiera B (2006) Paying too much and being happy about it: existence, causes, and consequences of tariff-choice biases. Journal of Marketing Research 43:212-223

Linde F (2008) Pricing-Strategien bei Informationsgütern. WISU 2:208-214

Lünendonk T (2007) Führende Standard-Software-Unternehmen in Deutschland. Studie der Lünendonk $\mathrm{GmbH}$, Bad Wörishofen

Nalebuff B (2004) Bundling as an entry barrier. Working Paper. School of Management, Yale University, New Haven

Nieschlag R, Dichtl E, Hörschgen H (2002) Marketing, 19th edn. Duncker \& Humblot, Berlin

Olderog T, Skiera B (2000) The benefits of bundling strategies. SBR 52(2):137-159

Pepels W (1998) Einführung in das Preismanagement. Oldenbourg, München

Pigou AC (1929) The economics of welfare, 3rd edn. Macmillian, London

Rullkötter L (2008) Preismanagement - Ein Sorgenkind? Zeitschrift für Controlling und Management 52(2):92-98

Schmalensee R (1984) Gaussian demand and commodity bundling. The Journal of Business 57:(1)211-230

Schmidt C, Weinhardt C, Horstmann R (1998) Internet-Auktionen - Eine Übersicht für OnlineVersteigerungen im Hard- und Softwarebereich. WIRTSCHAFTSINFORMATIK 40(5):450457

Schwartz E (2007) Calculating the cost of SaaS. In-

\section{Abstract}

Sonja Lehmann, Peter Buxmann

\section{Pricing Strategies of Software Vendors}

Due to the economic characteristics specific to the software industry, pricing concepts existing in other industries cannot be transferred without adaptation. Therefore, this article provides an overview of pricing models for software. In this context we discuss the six parameters formation of prices, structure of payment flow, assessment base, price discrimination, price bundling, and dynamic pricing strategies. Furthermore, we refer to recent software delivery models, such as Software as a service. The results are based on literature research and empirical studies.

Keywords: Pricing strategy, Software vendor, Software industry 
foworld, 2007-03-26, 6

Shapiro C, Varian HR (1999) Information rules: a strategic guide to the network economy. Harvard Business School, Boston

Shy $O$ (2001) The economics of network industries. Cambridge University, Cambridge

SIIA, Macrovision, SoftSummit, SVPMA, CELLUG (2006) Key trends in software pricing and licensing: a survey of software industry executives and their enterprise customers. http://www. siia.net/software/pubs/SW_Pricing_ Licensing_Report.pdf. Accessed 2009-03-10

Simon H (1992) Preismanagement: Analyse, Strategie, Umsetzung, 2nd edn. Gabler, Wiesbaden

Simonson I, Tversky A (1992) Choice in context: tradeoff contrast and extremeness aversion. Journal of Marketing Research 29(3):281-295

Skiera B, Spann M (1998) Gewinnmaximale zeitliche Preisdifferenzierung für Dienstleistungen. ZfB 68:703-718

Skiera B (1999a) Preisdifferenzierung. In: Albers S, Clement M, Peters K (eds) Marketing mit interaktiven Medien. Strategien zum Markterfolg. F.A.Z. Institut, Frankfurt am Main, pp 283-296

Skiera B (1999b) Mengenbezogene Preisdifferenzierung bei Dienstleistungen. Gabler, Wiesbaden

Skiera B, Spann M (2000) Flexible Preisgestaltung im Electronic Business. In: Weiber R (eds) Handbuch electronic Business: Informationstechno- logien - Electronic Commerce - Geschäftsprozesse. Gabler, Wiesbaden, pp 539-557

Skiera B, Spann M (2002) Preisdifferenzierung im Internet. In: Schögel M, Tomczak T, Belz C (eds) Roadm@p to E-Business. Thexis, St. Gallen, pp 270-284

Skiera B, Spann M, Walz U (2005) Erlösquellen und Preismodelle für den Business-to-Consumer-Bereich im Internet. WIRTSCHAFTSINFORMATIK 47(4):285-293

Smith GE, Nagle TT (1995) Frames of reference and buyers' perception of price and value. California Management Review 38(1):98-116

Suermann JC (2006) Bilanzierung von Software nach HGB, US-GAAP und IFRS - Integrative Analyse der Regelungen zu Ansatz, Bewertung und Umsatzrealisation von Software aus Hersteller- und Anwendersicht. Diss. Universität Würzburg. http://www.opus-bayern.de/uniwuerzburg/volltexte/2006/1933. Accessed 2009-03-10

Sundararajan A (2004) Nonlinear pricing of information goods. Management Science 50(12):1660-1673

Varian HR (1997) Versioning information goods. In: Kahin B, Varian HR (eds) Internet publishing and beyond: the economics of digital information and intellectual property. MIT, Cambridge, pp 190-202

Viswanathan S, Anandalingam G (2005) Pricing strategies for information goods. Sadhana Journal of the Indian Academy of Sciences 30(2,3):257-274

Wu S, Anandalingam G (2002) Optimal customized bundle pricing for information goods. In: Proceedings workshop on information technology and systems, Barcelona

Wu S, Hitt LM, Chen P, Anandalingam G (2008) Customized bundle pricing for information goods: a nonlinear mixed-integer programming approach. Management Science 54(3):608-622

Zerdick A, Picot A, Schrape K, Artopé A, Goldhammer K, Lange UT, Vierkant E, López-Escobar E, Silverstone R (1999) Die Internet-Ökonomie: Strategien für die digitale Wirtschaft, 2nd edn. Springer, Heidelberg

Zhang J, Seidmann A (2003) The optimal software licensing policy under quality uncertainty. ACM Press: Proceedings of the 5th international conference on electronic commerce. New York, pp 276-286 